\title{
An increased circulating blood volume does not prevent hypotension after pheochromocytoma resection
}

\author{
[Une augmentation du volume du sang circulant ne prévient pas l'bypotension \\ après la résection d'un phéochromocytome]
}

Takehiko Iijima DDS PhD DMSC, Toshiyuki Takagi MD, Yasuhide Iwao MD PhD

Purpose: Pulse dye-densitometry, a novel monitor that measures circulating blood volume (CBV) and cardiac output (CO), was used in patients with pheochromocytoma to determine the relationship between CBV and post resection hypotension.

Methods: Case control study. An $\alpha$ blocker was administered for approximately two weeks, and its effect on the expansion of CBV was quantified. CBV was monitored in seven patients admitted for resection of suspected pheochromocytoma before preoperative $\alpha$ blocker therapy, after $\alpha$-blocker therapy and three times during the operation. Relationships between the CBV and blood pressure after resection of the tumour were examined.

Results: CBV increased from $72.0 \pm 10.0 \mathrm{~mL} \cdot \mathrm{kg}^{-1}$ to $83.4 \pm 12.2$ $\mathrm{mL} \cdot \mathrm{kg}^{-1}$ after $\alpha$ blockade. $(P<0.00 \mathrm{l})$. We found a significant inverse relationship between the increase in CBV after $\alpha$-blocker therapy and blood pressure after resection of the tumour.

Conclusions: Expansion of the CBV by $\alpha$-blocker therapy was related to lower blood pressures after resection of the pheochromocytoma. Expansion of the CBV by an $\alpha$ blocker may have increased the elastance of blood vessels. Preoperative blood volume expansion does not preclude hypotension after tumour resection. Although the CBV value itself is not a predictor for hypotension after tumour resection, pulse dye-densitometry provides values of $\mathrm{CO}$ and $\mathrm{CBV}$ simultaneously, assisting in the management of volume resuscitation and/or the need for catecholamines.

Objectif : La sphygmo-densitométrie à colorant, un nouveau monitorage du volume du sang circulant (VSC) et du débit cardiaque (DC), a été utilisée chez des patients atteints de phéochromocytome pour déterminer la relation entre le VSC et l'hypotension postrésection.
Méthode : Une étude cas-témoins. Un agent $\alpha$ bloquant a été administré pendant deux semaines environ et son effet sur l'expansion du VSC a été quantifié. Le VSC a été suivi chez sept patients, admis pour la résection d'un phéochromocytome possible, avant le traitement préopératoire avec l' $\alpha$-bloquant, après le traitement et trois fois pendant l'opération. La relation entre le VSC et la tension artérielle postrésection tumorale a été examinée.

Résultats : Le VSC s'est accru de 72,0 $\pm 10,0 \mathrm{~mL} \cdot \mathrm{kg}^{-1}$ à 83,4 \pm $12,2 \mathrm{~mL} \cdot \mathrm{kg}^{-1}$ après le blocage $\alpha(P<0,00 \mathrm{l})$. Une relation inverse significative a été trouvée entre l'augmentation du VSC après le traitement $\alpha$-bloquant et la tension artérielle postrésection tumorale.

Conclusion : L'expansion du VSC par un traitement $\alpha$-bloquant a été reliée à une tension artérielle plus basse après la résection d'un phéochromocytome. L'expansion du VSC par un $\alpha$ bloquant peut avoir augmenté l'élastance des vaisseaux sanguins. L'expansion préopératoire du volume sanguin n'empêche pas l'incidence d'hypotension après la résection tumorale. Même si la valeur du VSC ne permet pas, en elle-même, de prédire l'hypotension après la résection d'une tumeur, la sphygmo-densitométrie à colorant fournit des valeurs simultanées de DC et de VSC, donnant ainsi des indications pour le rétablissement du volume sanguin et/ou le besoin de catécholamines.

I $\mathrm{N}$ patients with pheochromocytoma, a catecholamine-producing tumour, circulating blood volume $(\mathrm{CBV})$, is presumed to be in the lower than normal range. ${ }^{1} \mathrm{~A}$ decrease in $\mathrm{CBV}$ is thought to be responsible in part for hypotension after resection of the adrenal gland. However, no monitor of CBV has been previously available for bedside use. The

From the Department of Anesthesiology, Kyorin University School of Medicine, Tokyo, Japan.

Address correspondence to: Dr. Takehiko Iijima, Department of Anesthesiology, Kyorin University, 6-20-2 Shinkawa Mitaka-City,

Tokyo 181, Japan. Phone: +81-422-47-5511 ext. 2410 or 3544; Fax: +81-422-43-1504; E-mail: iijmt@kyorin-u.ac.jp

This study was not supported by any commercial institution.

Accepted for publication May 23, 2003.

Revision accepted November 28. 
significance of preoperative optimization of CBV for the hemodynamic management of these patients remains unclear. Pulse dye-densitometry (PDD), an application of pulse oximetry, is a newly developed monitor of plasma indocyanine green (ICG) concentration that allows calculation of CBV and cardiac output (CO) at the bedside. ${ }^{2}$ The values of $\mathrm{CBV}$ and $\mathrm{CO}$ have been validated previously. ${ }^{2-5}$ We applied this monitoring modality to patients with pheochromocytoma and examined the effect of preoperative administration of an $\alpha$ blocker on CBV. We examined the relationship between CBV and hypotension after tumour resection.

\section{Material and methods}

The experimental protocol was approved by the Research Committee of Kyorin University School of Medicine. Seven patients who were admitted to the Kyorin University Hospital in 1995-2001 were clinically diagnosed as having pheochromocytoma. They were informed of the study, and their consent was obtained. The patients took an $\alpha$ blocker (prazosin 1.5-10 mg), for approximately two weeks. PDD measurement was performed twice before and two weeks after treatment with an $\alpha$ blocker.

Anesthesia was induced with thiopental, fentanyl and vecuronium bromide and was maintained with a continuous infusion of propofol $\left(5-15 \mathrm{mg} \cdot \mathrm{kg}^{-1} \cdot \mathrm{hr}^{-1}\right)$. In addition, two patients received spinal anesthesia with tetracaine. In the other five patients, an epidural catheter was inserted for postoperative analgesia and allowed surgical analgesia with $1 \%$ mepivacaine. PDD (DDG analyzer ${ }^{\mathrm{TM}}$, Nihon Kohden Corp., Tokyo, Japan) was used to depict dye densitogram. A nose probe was attached to the nostril. Twenty milligrams of ICG diluted in $4 \mathrm{~mL}$ distilled water were injected through a central venous catheter inserted in the internal jugular vein. After a control PDD measurement was taken, surgery proceeded either by retroperitoneal laparoscopy $(n=$ $4)$, or via a retroperitoneal laparotomy $(n=3)$. Arterial blood pressure was monitored carefully after ligation of the adrenal gland vein, the values recorded and a continuous infusion of noradrenaline was titrated to counteract hypotension below $60 \mathrm{mmHg}$ of systolic blood pressure. PDD was measured during manipulation of the tumour and after tumour resection. Abrupt increases in blood pressure were treated by bolus injection of phentolamine 5 to $10 \mathrm{mg}$.

\section{Statistical analysis}

Values are expressed as mean \pm standard deviation (SD). The differences in CBV and $\mathrm{CO}$ were compared by analysis for variance of repeated measurements. StudentNewman-Keuls was used as a post hoc test. Significance

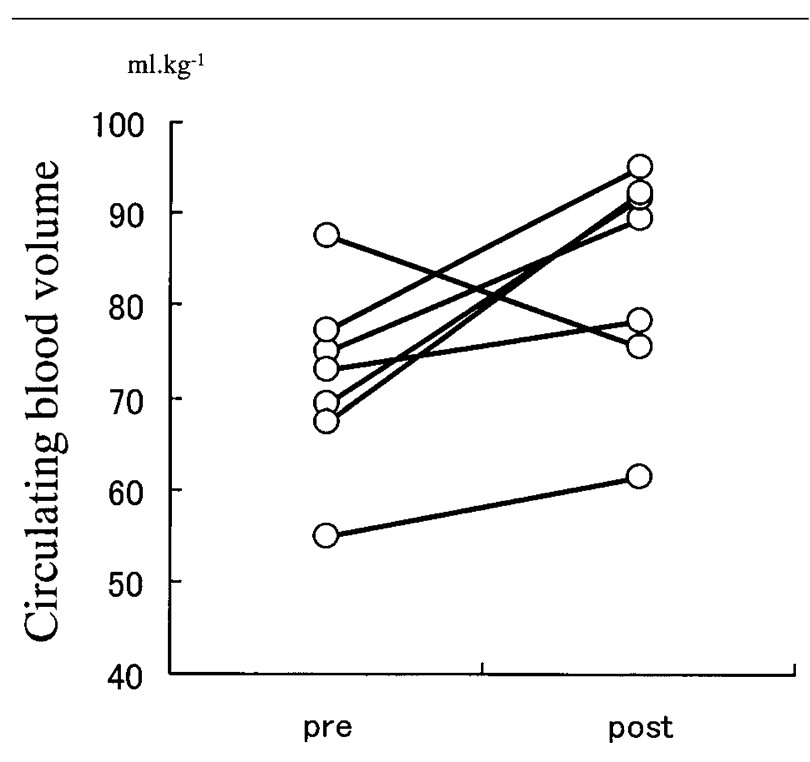

FIGURE 1 Expansion of circulating blood volume after $\alpha-$ blocker therapy

Circulating blood volume increased two weeks after $\alpha$-blocker administration in six out of seven patients with pheochromocytoma. Pre $=$ before $\alpha$-blocker administration; Post $=$ two weeks after $\alpha$-blocker administration.

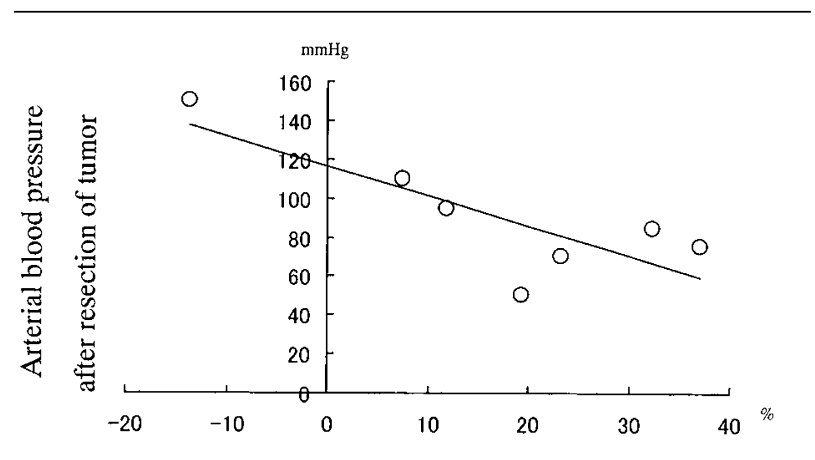

$\%$ increase in circulating blood volume after $\alpha$ blocker therapy

FIGURE 2 Relationship between volume expansion and blood pressure after resection of tumour

Blood volume expansion did not contribute to the prevention of hypotension after tumour resection. Expansion of blood volume was inversely correlated with post resection blood pressure $(\mathrm{r}=$ $0.802, P=0.03$ ).

of correlation was analyzed by conversion of $r$ to $t$ value. The Statview software version 5.0 (Brain Power, Calabasas, CA, USA) was used for the calculations. 
TABLE Intraoperative hemodynamics during anesthesia for resection of pheochromocytoma

\begin{tabular}{|c|c|c|c|c|c|c|}
\hline & $\begin{array}{l}\text { Sys BP } \\
(m m H g)\end{array}$ & $\begin{array}{l}\text { Dia BP } \\
(m m H g)\end{array}$ & $\begin{array}{l}H R \\
(\min )\end{array}$ & $\begin{array}{l}\text { CVP } \\
(m m H g)\end{array}$ & $\begin{array}{l}C O \\
\left(L \cdot \mathrm{min}^{-1}\right)\end{array}$ & $\begin{array}{l}C B V \\
(L)\end{array}$ \\
\hline After induction of anesthesia & $138 \pm 22$ & $52 \pm 7$ & $83 \pm 17$ & $11.6 \pm 6.6$ & $5.4 \pm 2.2$ & $5.6 \pm 1.9$ \\
\hline Before resection of tumour & $184 \pm 50 *$ & $102 \pm 31^{*}$ & $110 \pm 28 *$ & $10.6 \pm 4.8$ & $8.8 \pm 2.4^{*}$ & $5.0 \pm 1.4$ \\
\hline After resection of tumour & $100 \pm 28$ & $62 \pm 20$ & $94 \pm 21$ & $11.4 \pm 5.5$ & $6.6 \pm 3.1$ & $5.1 \pm 1.3$ \\
\hline
\end{tabular}

Sys $\mathrm{BP}=$ systolic arterial blood pressure $; \mathrm{Dia} \mathrm{BP}=$ diastolic arterial blood pressure $\mathrm{HR}=\mathrm{heart}$ rate; $\mathrm{CVP}=\mathrm{central}$ venous pressure; $\mathrm{CO}=$ cardiac output; $\mathrm{CBV}$ = circulating blood volume measured by pulse dye-densitometry, ${ }^{*} P<0.01$. Blood pressure increased during tumour manipulation (before resection of tumour), accompanied by a significant increase in CO. CBV declined slightly during surgery, but the variation was not statistically significant.

\section{Results}

The CBV increased from $72.0 \pm 10.0 \mathrm{~mL} \cdot \mathrm{kg}^{-1}$ to 83.4 $\pm 12.2 \mathrm{~mL} \cdot \mathrm{kg}^{-1}$ (from $3.71 \pm 0.79 \mathrm{~L}$ to $4.30 \pm 0.98 \mathrm{~L}$; $P<0.01)$ after two weeks treatment with an $\alpha$-blocker alone (Figure 1: six increased, one decreased). Arterial blood pressure and $\mathrm{CO}$ significantly increased during manipulation of the tumour, although CBV remained unchanged (Table). We did not find any relationship between the catecholamine values, [plasma noradrenaline, urine noradrenaline, plasma vanillylmandelic acid (VMA) and urine VMA] and CBV. We found a significant inverse relationship between expansion of CBV and lowest blood pressure after tumour resection (Figure 2: $\mathrm{r}=-0.802, P=0.03$ ).

\section{Discussion}

We had hypothesized that an increase in CBV by $\alpha$ blocker therapy or a high CBV would prevent hypotension after tumour resection. Contrary to our expectations, neither the absolute CBV value nor the increase in CBV after $\alpha$-blocker therapy had any relationship with blood pressure. Thus, optimization of CBV by $\alpha$-blocker therapy does not seem to have a strong impact on hemodynamic stability after tumour resection. The observed significant inverse relation between the expansion of CBV and blood pressure after tumour resection may be related to the increased elastance of the vascular tree after $\alpha$-blocker therapy.

Previously, CBV was measured with radioisotopes (RI). Therefore, its use has been limited because of the biohazard involved. PDD, a novel bedside monitor, enabled us to quantify CBV repeatedly. The accuracy of the values obtained by PDD has been confirmed by comparison with the gold standard RI method. ${ }^{2}$ The CBV is reportedly lowered in patients with pheochromocytoma. ${ }^{1}$ However, in the present study, we failed to find a correlation between urine VMA and CBV. Hirasawa et al. reported a significant correlation between serum noradrenaline and CBV. ${ }^{6}$ Therefore, the relationship between catecholamine levels and CBV appears to be weak, possibly because CBV varies between individuals. ${ }^{3}$ We observed that CBV increased after $\alpha$ blocker administration with only one exception. The latter patient had advanced arteriosclerosis and his blood pressure did not decline after tumour resection. This patient's hypertension persisted even after his serum and urine catecholamine levels normalized. Stenstrom et al. also observed that, in patients with pheochromocytoma, CBV increased with treatment in individuals with paroxysmal hypertension, but did not increase in the group with sustained hypertension.?

In summary, CBV was not a predictor of post resection hypotension. Nonetheless, CO and CBV proved useful to decide whether catecholamine supplementation or volume loading was required to increase blood pressure after ligation of the adrenal vein.

\section{References}

1 Deoreo GA Jr, Stewart BH, Tarazi RC, Gifford RW Jr. Preoperative blood transfusion in the safe surgical management of pheochromocytoma: a review of 46 cases. J Urol 1974; 111: 715-21.

2 Iijima T, Iwao $\Upsilon$, Sankawa $H$. Circulating blood volume measured by pulse dye-densitometry. Comparison with ${ }^{131}$ I-HSA analysis. Anesthesiology 1998; 89: 1329-35.

3 Iijima T, Aoyagi T, Iwao $\Upsilon$, et al. Cardiac output and circulating blood volume analysis by pulse dye-densitometry. J Clin Monit 1997; 13: 81-9.

4 Imai T, Takahashi K, Fukura H, Morishita $\Upsilon$. Measurement of cardiac output by pulse dye densitometry using indocyanine green. A comparison with the thermodilution method. Anesthesiology 1997; 87: 816-22.

5 Ueyama H, He $\Upsilon L$, Tanigami H, Mashimo T, Yoshiya I. Effects of crystalloid and colloid preload on blood volume in the parturient undergoing spinal anesthesia for elective cesarean section. Anesthesiology 1999; 91: 1571-6. 
6 Hirasawa K, Kasuya H, Hori T. Change in circulating blood volume following craniotomy. J Neurosurg 2000; 93: 581-5.

7 Stenstrom G, Kutti J. The blood volume in pheochromocytoma patients before and during treatment with phenoxybenzamine. Acta Med Scan 1985; 218: 381-7.

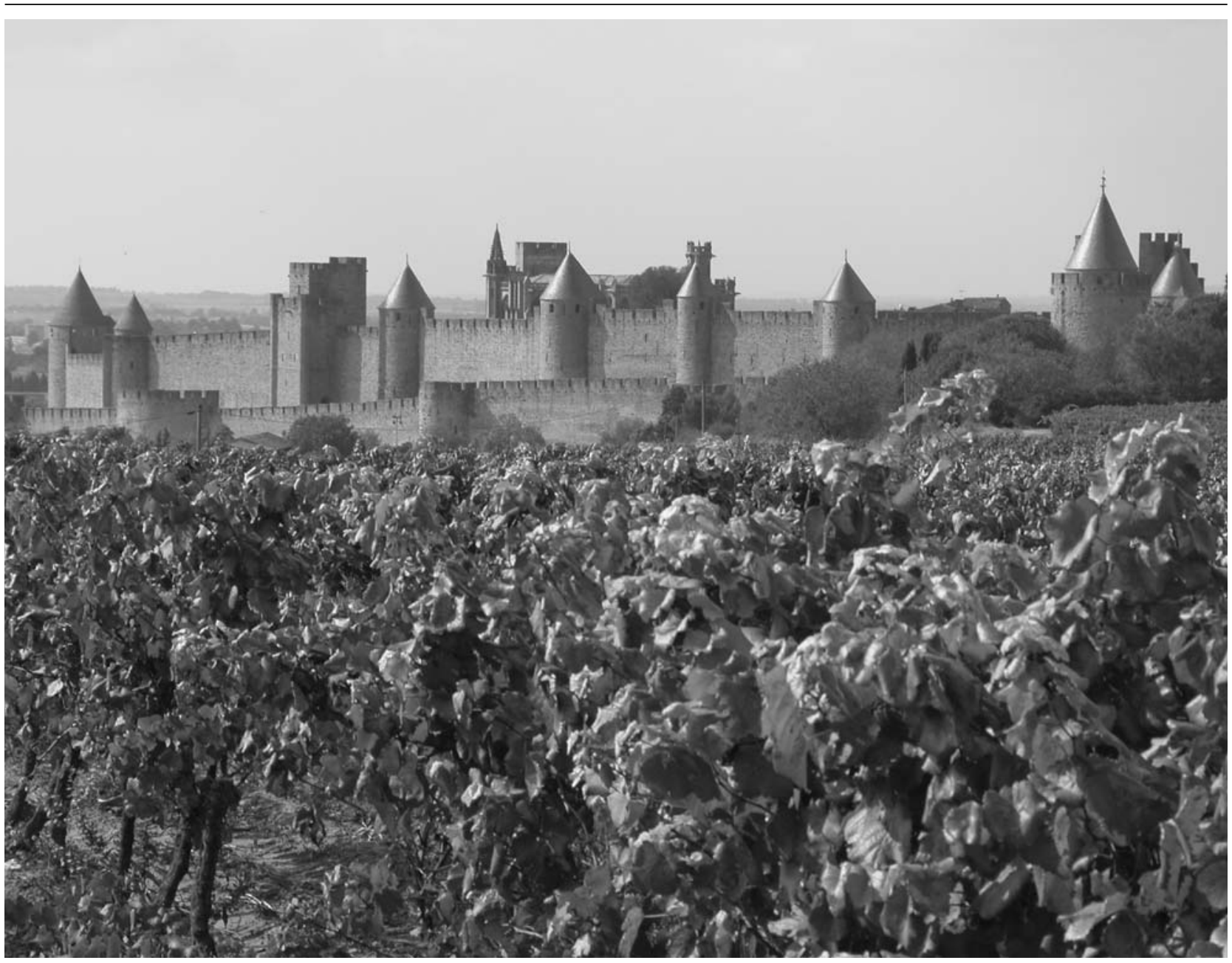

Cité médiévale de Carcassonne 